Arq. Bras. Med. Vet. Zootec., v.71, n.3, p.741-751, 2019

\section{Perfil metabólico de vacas Holandês e mestiças Holandês x Jersey no periparto}

[Metabolic profile of Holstein and crossbred Holstein x Jersey cows in the peripartum]
A. Pelizza

https://orcid.org/0000-0002-1155-9745 A. Hauser

https://orcid.org/0000-0002-5024-1668 T.C. Mendes

https://orcid.org/0000-0002-1856-4424 C.A. Mattiello https://orcid.org/0000-0001-7302-5506 D.A. Knob

https://orcid.org/0000-0003-3972-1094 L.L. Cardozo https://orcid.org/0000-0003-1006-0771 R. Parizotto Filho https://orcid.org/0000-0003-1901-654X I.P.O. Gomes https://orcid.org/0000-0001-9765-4139 D.R.M. Alessio M. Camera https://orcid.o (1) https://orcid.org/0000-0003-4850-1341

${ }^{3}$ Aluno de graduação, Universidade do Estado de Santa Catarina - Lages, SC ${ }^{4}$ Universidade do Estado de Santa Catarina - Lages, SC

\title{
RESUMO
}

O objetivo do presente trabalho foi determinar e comparar o perfil metabólico de vacas Holandês $(\mathrm{H})$ e mestiças Holandês x Jersey (HxJ) no periparto. Avaliaram-se 24 vacas, sendo 11 vacas Holandês e 13 mestiças Holandês $x$ Jersey. Semanalmente, coletou-se sangue para a determinação das concentrações séricas de glicose, beta-hidroxibutirato (BHB), proteína total, albumina, aspartato aminotransferase (AST), creatinoquinase (CK), cálcio total, cálcio iônico, magnésio, fósforo inorgânico e colesterol. Avaliou-se também o peso vivo e o escore de condição corporal (ECC). Os dados foram submetidos à análise de variância com medidas repetidas no tempo. As vacas Holandês apresentaram maior peso vivo. Não houve diferença entre os grupamentos genéticos para ECC. Foi observada tendência de maiores concentrações séricas de BHB, AST e maior concentração de cálcio iônico em vacas mestiças Holandês $x$ Jersey. Vacas mestiças Holandês x Jersey e Holandês apresentaram perfil energético similar durante $o$ período de transição pré e pós-parto na maioria dos indicadores, com exceção do cálcio, que foi maior nas vacas mestiças, e do fósforo, que foi superior nas vacas Holandês.

Palavras-chave: cruzamento, hipocalcemia, enzimas hepáticas

\begin{abstract}
The aim of this study was to determine and compare the metabolic profile of Holstein $(H)$ and crossbred Holstein x Jersey (HxJ) on peripartum. For this, 24 cows were evaluated, 11 Holstein and 13 crossbreeds Holstein $x$ Jersey. Weekly, venous blood sample were collected to determine concentration of glucose, beta-hydroxybutyrate (BHBA), total protein, albumin, aspartate aminotransferase (AST), creatine kinase $(C K)$, total calcium, ionic calcium, magnesium, inorganic phosphorus and cholesterol. Body weight (BW) and body condition score (BCS) were also evaluated. The data were submitted to analysis of variance with repeated measures in time. Holstein cows presented higher $B W$, however, there was no difference for $B C S$ in compare to crossbreed Holstein $x$ Jersey cows. Tendency for higher serum concentrations of $B H B A, A S T$ and higher concentration of ionic calcium was observed in crossbreed cows in comparison to the Holstein. The energetic profile during the pre and postpartum transition period is similar for both genetic groups with higher concentrations of BHBA on the first week of lactation, however, with a tendency of higher serum concentrations of BHBA for crossbreed cows. Higher concentrations of ionic calcium were observed in crossbreed cows and higher concentrations of phosphorus in Holstein cows on peripartum. Holstein and Holtein x Jersey crossbreed cows have a similar energy profile during the pre and postpartum transition period in most of the indicators, except for calcium that was higher in crossbred cows and higher phosphorus in Holstein cows.
\end{abstract}

Keywords: crossbreed, hypocalcemia, hepatic enzymes

Recebido em 17 de junho de 2017

Aceito em 9 de outubro de 2018

E-mail: angelapelizza@hotmail.com 


\section{INTRODUÇÃO}

O período de transição caracteriza-se por uma fase crítica, especialmente para vacas de alta produção leiteira. A maioria das vacas passam por uma fase de redução do consumo de alimentos, balanço energético negativo, cetose, hipocalcemia, redução da função imune e infecções uterinas (Leblanc, 2010). O monitoramento de rebanhos leiteiros torna-se imprescindível nessa fase da vida produtiva e possibilita a detecção precoce de problemas relacionados à saúde, tornando possível a prevenção e evitando o agravamento de muitos distúrbios. Nessa fase, mudanças de manejo e de alimentação também podem ser implementadas para diminuir as perdas produtivas e econômicas. $\mathrm{O}$ monitoramento de doenças pode ser realizado por meio de indicadores sanguíneos em um grupo representativo de animais, os quais podem ser utilizados para avaliar as principais vias metabólicas relacionadas à energia, proteínas e minerais, bem como à funcionalidade de órgãos vitais, como o fígado (Wittwer, 2000; González et al., 2011).

No período de transição, o balanço energético negativo ocorre com maior ou menor intensidade e é um reflexo das mudanças metabólicas e fisiológicas que acontecem no organismo da vaca para a manutenção da homeostase, do manejo a que está sendo submetida, da alimentação que recebe e das condições de conforto e bem-estar. Nessa fase, a vaca utiliza energia proveniente dos depósitos de gordura corporal que são mobilizados, como ácidos graxos não esterificados (AGNE) (Bauman e Currie, 1980). A capacidade da completa oxidação de AGNE pelo fígado é limitada, o que conduz à formação de corpos cetônicos, acetona, acetoacetato e betahidroxibutirato (BHB) no plasma, à reesterificação e ao acúmulo de triglicerídeos no fígado (Schäff et al., 2013; Kessler et al., 2014). A oxidação excessiva de ácidos graxos, juntamente com a deficiência de energia na dieta, pode causar cetose (González e Silva, 2006).

Durante o período de transição, o catabolismo proteico também ocorre e pode ser influenciado pela nutrição, pelos processos do parto e pela lactação. A análise de proteína total e albumina no soro ou no plasma permite diagnosticar problemas relativos ao metabolismo proteico (González e Silva, 2006).
Um adequado metabolismo e aporte de macrominerais e microminerais refletem diretamente na saúde de vacas leiteiras. A hipocalcemia é a doença metabólica mais comum em vacas leiteiras recém-paridas (González e Silva, 2006). Chamberlin et al. (2013) encontraram $51 \%$ de vacas com hipocalcemia subclínica no parto, tendo as vacas recuperado o nível de Ca iônico até o terceiro dia após o parto. $\mathrm{Na}$ hipocalcemia subclínica, apesar de não apresentar doença clínica, a vaca fica mais suscetível à ocorrência de outras doenças, como febre, metrite, retenção de placenta, além de diminuição da função de células (Martinez et al., 2014).

O cruzamento entre as raças Holandês e Jersey tem sido empregado como alternativa para a melhoria da qualidade do leite, em termos de composição, com maior nível de sólidos (proteína e gordura) (Lopez-Villalobos et al., 2000). Esse sistema de cruzamento vem sendo realizado em diversos países, destacando-se a Nova Zelândia, onde os resultados apontam para o aumento da lucratividade por vaca e por área (Lopez-Villalobos et al., 2000). Trabalhos de outros grupos de pesquisa mostram que vacas mestiças produzem leite com maior teor de gordura e proteína (Heins et al., 2008; Prendiville et al., 2009) e apresentam maior fertilidade, indicada por um menor período de dias em aberto, quando comparadas com vacas Holandês (Heins et al., 2012).

No sul do Brasil, alguns produtores iniciaram programas de cruzamentos, porém há falta de informação em relação às vacas mestiças Holandês x Jersey, tornando isso uma barreira para o uso de cruzamentos. Historicamente, a raça mais difundida para a produção de leite foi a Holandês, ao mesmo tempo, sempre se deu grande ênfase no melhoramento para aspectos produtivos e de conformação. A elevada produção de leite tornou essa raça mais suscetível a doenças e problemas reprodutivos. Assim, este trabalho, ao comparar o perfil metabólico de vacas Holandês e mestiças Holandês x Jersey em condições experimentais, ajuda a suprir a falta de informação na literatura científica mundial e permite identificar como esses animais reagem ao período de transição, de muitas mudanças fisiológicas e metabólicas e de estresse intenso, de elevada demanda de energia e em que a vaca ainda tem uma ingestão de 
alimento inadequada para suprir suas necessidades. Permite saber, portanto, sobre a saúde das vacas, e esse conhecimento pode ser utilizado como base para programas de cruzamentos. A hipótese deste trabalho é a de que existem diferenças metabólicas entre vacas Holandês e mestiças Holandês x Jersey, que podem explicar uma maior saúde e um melhor desempenho reprodutivo das vacas mestiças. Assim, o objetivo do presente trabalho foi determinar e comparar o perfil metabólico de vacas mestiças Holandês x Jersey com o de vacas da raça Holandês no período de transição pré e pós-parto.

\section{MATERIAL E MÉTODOS}

Todos os procedimentos envolvendo as vacas do experimento foram aprovados pelo Comitê de Ética e Experimentação Animal da Universidade do Estado de Santa Catarina, com número de protocolo 01.51.14. O experimento foi realizado no setor de Bovinocultura de Leite da Universidade do Estado de Santa Catarina Udesc, em Lages, SC, Brasil, localizado nas coordenadas $27^{\circ} 47^{\prime} 06.32^{\prime \prime} \mathrm{S}$ e $50^{\circ} 18^{\prime} 16.76^{\prime} \mathrm{O}$, com altitude de 914 metros. Foram utilizadas 24 vacas, sendo 11 da raça Holandês (seis primíparas e cinco multíparas) e 13 mestiças Holandês x Jersey (quatro primíparas e nove multíparas). As vacas foram alojadas em piquetes coletivos, três semanas antes da data prevista do parto, e, após o parto, foram alojadas em baias individuais, com acesso livre ao alimento e à água. As dietas dos animais foram formuladas para atender $100 \%$ das exigências nutricionais, de acordo com o NRC (Nutrient..., 2001) (Tab. 1), sendo fornecida na forma de dieta total (TMR). A quantidade ofertada para cada animal foi ajustada diariamente, a fim de proporcionar sobras entre cinco e 10 por cento.

Tabela 1. Composição e constituição bromatológica da dieta com base na matéria seca (MS) fornecida às vacas no pré-parto e no pós-parto

\begin{tabular}{lcc}
\hline \multicolumn{1}{c}{ Ingredientes (\% de MS) } & Pré-parto & Pós-parto \\
\hline Feno de alfafa & - & 12,90 \\
Silagem de milho & 67,90 & 44,70 \\
Milho moído & 15,60 & 20,60 \\
Farelo de soja & 14,70 & 18,90 \\
Ureia & 0,40 & - \\
Minerais e vitaminas & 1,50 & 1,90 \\
Bicarbonato de sódio & - & 1,00 \\
& Composição química & \\
PB & 14,83 & \\
FDN & 34,11 & 17.20 \\
FDA & $1, .05$ & 31.78 \\
EE & 2,09 & 16,35 \\
Cinzas & 5,80 & 2,29 \\
CNF & 40,03 & 7,80 \\
K & 1,49 & 43,84 \\
Na & 0,44 & 1,92 \\
Cl & 0,29 & 0,40 \\
S & 0,21 & 0,31 \\
Ca & 0,46 & 0,26 \\
P & 0,34 & 0,69 \\
Mg & 0,24 & 0,40 \\
DCAD (mEq/100g de MS) & $+35,94$ & 0,26 \\
& & $+41,54$ \\
\hline
\end{tabular}

Não foi utilizada dieta aniônica no período préparto, com o objetivo de não mascarar eventuais diferenças no metabolismo das vacas dos dois grupamentos genéticos avaliados. O suplemento mineral e vitamínico fornecido para as vacas no pré e pós-parto foi o Novo Bovigold (DSM Tortuga, Mairinque, São Paulo, Brasil).

Para a realização das análises bromatológicas, foram coletadas semanalmente amostras individuais de silagem de milho, feno de alfafa e 
concentrado. As amostras foram submetidas à secagem em estufa com ventilação forçada (Solab SL-31, Piracicaba, Brasil) a $60^{\circ} \mathrm{C}$, durante 72 horas, e posteriormente moídas em peneira de $1 \mathrm{~mm}$. Para determinar o teor de matéria seca (MS), as amostras moídas foram submetidas à secagem em estufa a $105^{\circ} \mathrm{C}$, por 24 horas. As amostras de cada alimento coletadas ao longo das semanas foram agrupadas para posterior análise química. A matéria mineral foi determinada por queima em forno mufla a $550^{\circ} \mathrm{C}$, durante quatro horas. $\mathrm{O}$ teor de fibra em detergente neutro (FDN) foi determinado conforme proposto por Mertens et al. (2002). O teor de nitrogênio total foi determinado pelo método Kjeldahl (Official..., 1990), e o teor de extrato etéreo (EE) foi determinado em um extrator Soxhlet, com éter etílico a $180^{\circ} \mathrm{C}$, por quatro horas. Os carboidratos não fibrosos (CNF) foram obtidos pelo cálculo por diferença, por meio da formula: $\mathrm{CNF}=100-(\% \mathrm{FDN}+\% \mathrm{~PB}+$ $\%$ Gordura + \%Cinzas). A diferença catiônica e aniônica da dieta (DCAD) foi calculada usandose a seguinte equação: DCAD $(\mathrm{mEq} / 100 \mathrm{~g}$ de $\mathrm{MS})=(\mathrm{mEq}$ de $\mathrm{Na}+\mathrm{mEq}$ de $\mathrm{K})-(\mathrm{mEq}$ de $\mathrm{S}+$ mEq de $\mathrm{Cl}$ ) (Nutrient..., 2001).

As avaliações de escore de condição corporal (ECC), peso vivo e as coletas de amostras sanguíneas tiveram início após a ordenha da manhã, duas semanas antes da data prevista de parto até a oitava semana após o parto. A produção de leite individual de vaca foi medida diariamente por meio de medidores de leite Waikato $^{\circledR}$ Multi Meter. Os animais foram pesados e o ECC foi estimado conforme metodologia descrita por Ferguson et al. (1994).

Amostras sanguíneas foram coletadas por punção da veia jugular, utilizando-se sistema a vácuo com tubos de plástico seco com ativador de coágulo, revestidos de silicone. As amostras foram centrifugadas a $3000 \mathrm{~g}$, durante 10 minutos, para obtenção do soro, e, em seguida, congeladas a $-20^{\circ} \mathrm{C}$. As determinações de proteína total, albumina, aspartato aminotransferase (AST), creatinoquinase (CK), cálcio total, magnésio e colesterol foram feitas por colorimetria, mediante o uso de kits comerciais (Gold Analisa Diagnóstica, Belo Horizonte, Minas Gerais, Brasil), e a de fósforo inorgânico, por meio da utilização de kits comerciais (Vida Biotecnologia, Belo Horizonte,
Minas Gerais, Brasil). As determinações colorimétricas foram realizadas em um analisador bioquímico semiautomático (Bioplus 200S, Barueri, São Paulo, Brasil). A concentração sanguínea de BHB foi determinada utilizando-se um analisador portátil Option Xceed (Abott, São Paulo, Brasil). Coletou-se, também, sangue da artéria auricular caudal, por meio do uso de seringas de $1 \mathrm{~mL}$, previamente heparinizadas, e a partir dessas amostras, determinou-se a concentração de cálcio iônico, utilizando-se um analisador clínico portátil de gases sanguíneos, I-STAT (Chicago, Illinois, EUA) e cartuchos CG8+.

Os dados foram submetidos à análise de variância, com medidas repetidas no tempo dentro da variável aleatória vaca, utilizando-se o procedimento MIXED do pacote estatístico SAS, com estrutura de covariância autorregressiva, baseado no critério de informação de Akaike (AIC). Os dados foram previamente testados para normalidade dos resíduos pelo teste de Kolmogorov-Smirnov. O modelo estatístico incluía os efeitos das variáveis grupamento genético (Holandês e mestiças Holandês $\mathrm{x}$ Jersey), paridade (primíparas e multíparas), período (pré-parto e pós-parto), semana aninhada dentro do período e das interações do grupamento genético com período, grupamento genético com paridade, grupamento genético com semana dentro de período e paridade com semana dentro de período. Foram consideradas significativas as diferenças ao nível de $5 \%$ de significância e a tendência ao nível de $10 \%$.

\section{RESULTADOS}

As vacas da raça Holandês produziram mais leite $(\mathrm{P}=0,0002)$ em relação às vacas mestiças Holandês x Jersey (34,33 versus $29,05 \mathrm{~kg} / \mathrm{dia})$. Não houve diferença para o ECC entre vacas Holandês e mestiças Holandês x Jersey, sendo apenas observado efeito de semana $(\mathrm{P}<0,0001)$, com diminuição do ECC no pós-parto em ambos os grupamentos genéticos (Tab. 2 e Fig. 1A). Observou-se maior peso vivo nas vacas Holandês em comparação às mestiças Holandês x Jersey $(\mathrm{P}<0,0001)$. Foi observado efeito do período $(\mathrm{P}<0,0001)$ com maior peso vivo no período préparto em relação ao pós-parto (Tab. 2 e Fig. 1B). 


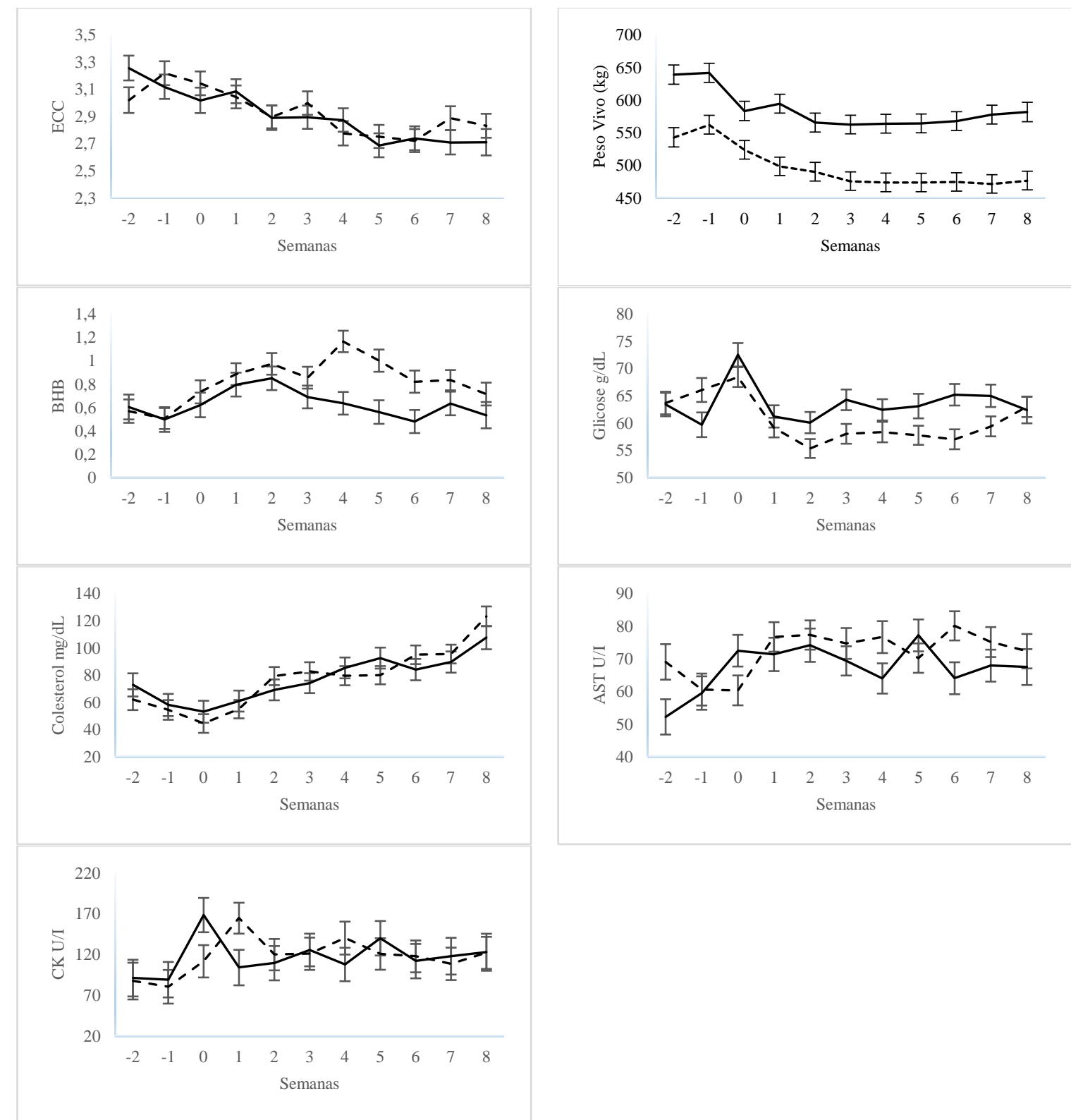

Figura 1. Escore de condição corporal, ECC (A), peso vivo (B), beta-hidroxibutirato, BHB (C), glicose (D), colesterol (E), aspartato aminotransferase, AST (F) e creatinoquinase, CK (G), em função das semanas em lactação para vacas Holandês (-) e mestiças Holandês x Jersey (- - -).

Foi observada uma tendência de maiores concentrações séricas de BHB em vacas mestiças Holandês $\mathrm{x}$ Jersey em relação às vacas Holandês $(\mathrm{P}=0,0874)$, com efeito do período e interação entre grupamento genético e período, tendo ocorrido as diferenças somente no pós-parto (Tab. 2). Observaram-se menores concentrações séricas de BHB durante o período pré-parto e maiores concentrações após o parto, principalmente da quarta até a sexta semana pósparto, em vacas mestiças Holandês x Jersey (Fig. 1C). Por outro lado, a concentração sérica de glicose não diferiu entre os grupos genéticos, assim como entre períodos (Tab. 2), havendo interação entre grupamento genético e período. 
Tabela 2. Médias dos quadrados mínimos \pm erros-padrão das médias e valor de $\mathrm{P}$ de grupamento genético (GG), período (Per) e interação de grupamento genético e período (GG*Per) para peso vivo, escore de condição corporal (ECC), concentração de beta-hidroxibutirato (BHB), glicose e colesterol em vacas Holandês $(\mathrm{H})$ e mestiças Holandês x Jersey (M) nos períodos pré e pós-parto

\begin{tabular}{lcccccc}
\multirow{2}{*}{ Variável } & GG & \multicolumn{2}{c}{ Período } & \multicolumn{3}{c}{ Valor de P } \\
& & Pré-parto & Pós-parto & GG & Per & GG*Per \\
\hline \multirow{2}{*}{ ECC } & H & $3,170 \pm 0,087$ & $2,85 \pm 0,070$ & \multirow{2}{*}{0,8583} & $<0,0001$ & 0,7562 \\
& M & $3,140 \pm 0,078$ & $2,848 \pm 0,063$ & & & \\
Peso vivo (kg) & H & $645,65 \pm 15,11$ & $573,27 \pm 13,71$ & $<0,0001$ & $<0,0001$ & 0,6209 \\
& M & $540,28 \pm 13,47$ & $473,77 \pm 12,37$ & & & \\
BHB (mmol/L) & H & $0,549 \pm 0,09$ & $0,643 \pm 0,057$ & 0,0874 & 0,0005 & 0,040 \\
Glicose & M & $0,535 \pm 0,082$ & $0,886 \pm 0,051$ & & & \\
(mg/dL) & H & $61,51 \pm 1,70$ & $63,997 \pm 0,93$ & 0,4074 & 0,2579 & 0,0017 \\
Colesterol & M & $64,84 \pm 1,65$ & $59,57 \pm 0,82$ & & & \\
(mg/dL) & H & $65,33 \pm 7,10$ & $79,50 \pm 4,72$ & 0,7655 & $<0,0001$ & 0,2939 \\
\hline
\end{tabular}

A concentração sérica de colesterol não diferiu entre os grupos genéticos avaliados $(\mathrm{P}=0,7655)$. Observou-se apenas diferença entre o período de avaliação $(\mathrm{P}<0,0001) \quad$ com menores concentrações de colesterol no período pré-parto em relação ao período pós-parto, com posterior aumento para ambos os grupamentos genéticos (Fig. 1E).

Houve uma tendência para maiores concentrações da enzima AST em vacas mestiças Holandês x Jersey em relação às vacas Holandês $(\mathrm{P}=0,0530)$ e, também, diferenças entre o período de avaliação $(\mathrm{P}<0,0001)$, com menores concentrações séricas de AST no período préparto e maiores no pós-parto, principalmente nas primeiras semanas de lactação para ambos os grupos genéticos (Tab. 3 e Fig. 1F). Não foram encontradas diferenças entre os grupamentos genéticos $(\mathrm{P}=0,9460)$ para as concentrações da enzima CK, havendo, porém, diferenças entre os períodos de avaliação, com menores concentrações antes do parto em relação ao pósparto (Tab. 3 e Fig. 1G).

Não foram observadas diferenças entre o grupamento genético para a concentração proteína total (Tab. 3), sendo apenas observada diferença entre período de avaliação, com menores concentrações de proteína total no préparto em relação ao pós-parto. Observou-se o aumento gradativo das concentrações séricas de proteína total a partir do parto em ambos os grupamentos genéticos (Fig. 2D). Para a variável albumina, não houve diferença entre os grupamentos genéticos $(\mathrm{P}=0,1437)$ e não foram observadas diferenças entre período de avaliação pré e pós-parto (Tab. 3).

Tabela 3. Médias dos quadrados mínimos \pm erros-padrão das médias (EPM) e valor de P de grupamento genético (GG), período (Per) e interação de grupamento genético e período (GG*Per) para creatinoquinase $(\mathrm{CK})$, aspartato aminotransferase (AST) proteína total e albumina nos períodos pré e pósparto

\begin{tabular}{lcccccc}
\multicolumn{1}{c}{ Variável } & \multirow{2}{*}{ GG } & \multicolumn{2}{c}{ Período } & \multicolumn{3}{c}{ Valor de P } \\
& & Pré-parto & Pós-parto & GG & Per & GG*Per \\
\hline \multirow{2}{*}{ CK (U/L) } & H & $89,91 \pm 18,55$ & $122,85 \pm 15,30$ & \multirow{2}{*}{0,9460} & $<0,0001$ & 0,6477 \\
& M & $83,75 \pm 17,92$ & $124,89 \pm 14,22$ & & & \\
AST (U/L) & $\mathrm{H}$ & $55,82 \pm 3,97$ & $69,73 \pm 2,07$ & 0,0530 & 0,0001 & 0,3868 \\
Proteína total & $\mathrm{M}$ & $64,78 \pm 3,86$ & $73,67 \pm 1,99$ & & & \\
(g/dL) & $\mathrm{H}$ & $6,89 \pm 0,65$ & $8,04 \pm 0,58$ & 0,4788 & $<0,0001$ & 0,4734 \\
Albumina (g/dL) & $\mathrm{M}$ & $7,66 \pm 0,60$ & $8,46 \pm 0,53$ & & & \\
& $\mathrm{H}$ & $2,83 \pm 0,13$ & $2,64 \pm 0,09$ & 0,1437 & 0,1790 & 0,2548 \\
\hline
\end{tabular}


As vacas mestiças Holandês $\mathrm{x}$ Jersey apresentaram maiores concentrações séricas de cálcio iônico em relação às vacas da raça Holandês $(\mathrm{P}=0,0294)$, sem diferir para as concentrações séricas de cálcio total $(\mathrm{P}=0,5724)$ e de magnésio $(\mathrm{P}=0,2805)$ durante o período de estudo. Entretanto, as concentrações séricas de fósforo foram superiores para as vacas da raça Holandês em relação às mestiças Holandês $\mathrm{x}$ Jersey $(\mathrm{P}=0,0012)$ (Tab. 4).

Tabela 4. Médias dos quadrados mínimos \pm erros-padrão das médias e valor de $\mathrm{P}$ de grupamento genético (GG), período (Per) e interação de grupamento genético e período (GG*Per) para as concentrações de cálcio iônico, cálcio total, magnésio e fósforo nos períodos pré e pós-parto

\begin{tabular}{|c|c|c|c|c|c|c|}
\hline \multirow{2}{*}{ Variável } & \multirow{2}{*}{ GG } & \multicolumn{2}{|c|}{ Período } & \multicolumn{3}{|c|}{ Valor de P } \\
\hline & & Pré-parto & Pós-parto & GG & Per & GG*Per \\
\hline Ca iônico & $\mathrm{H}$ & $0,83 \pm 0,04$ & $0,84 \pm 0,02$ & & & \\
\hline$(\mathrm{mmol} / \mathrm{L})$ & M & $0,95 \pm 0,03$ & $0,88 \pm 0,02$ & 0,0294 & 0,2415 & 0,1021 \\
\hline Ca total & $\mathrm{H}$ & $9,09 \pm 1,28$ & $11,13 \pm 1,04$ & & & \\
\hline (mg/dL) & M & $11,35 \pm 1,16$ & $10,86 \pm 0,93$ & $0,5 / 24$ & 0,2122 & 0,0411 \\
\hline Magnésio & $\mathrm{H}$ & $2,40 \pm 0,24$ & $2,24 \pm 0,17$ & & & \\
\hline$(\mathrm{mg} / \mathrm{dL})$ & M & $2,02 \pm 0,22$ & $2,14 \pm 0,15$ & 0,8824 & 0,2905 & 0,9858 \\
\hline Fósforo & $\mathrm{H}$ & $6,38 \pm 0,78$ & $7,81 \pm 0,43$ & 00012 & 07247 & 08305 \\
\hline (mg/dL) & $\mathrm{M}$ & $5,81 \pm 0,74$ & $5,96 \pm 0,40$ & 0,0012 & $0, / 24 /$ & 0,8395 \\
\hline
\end{tabular}
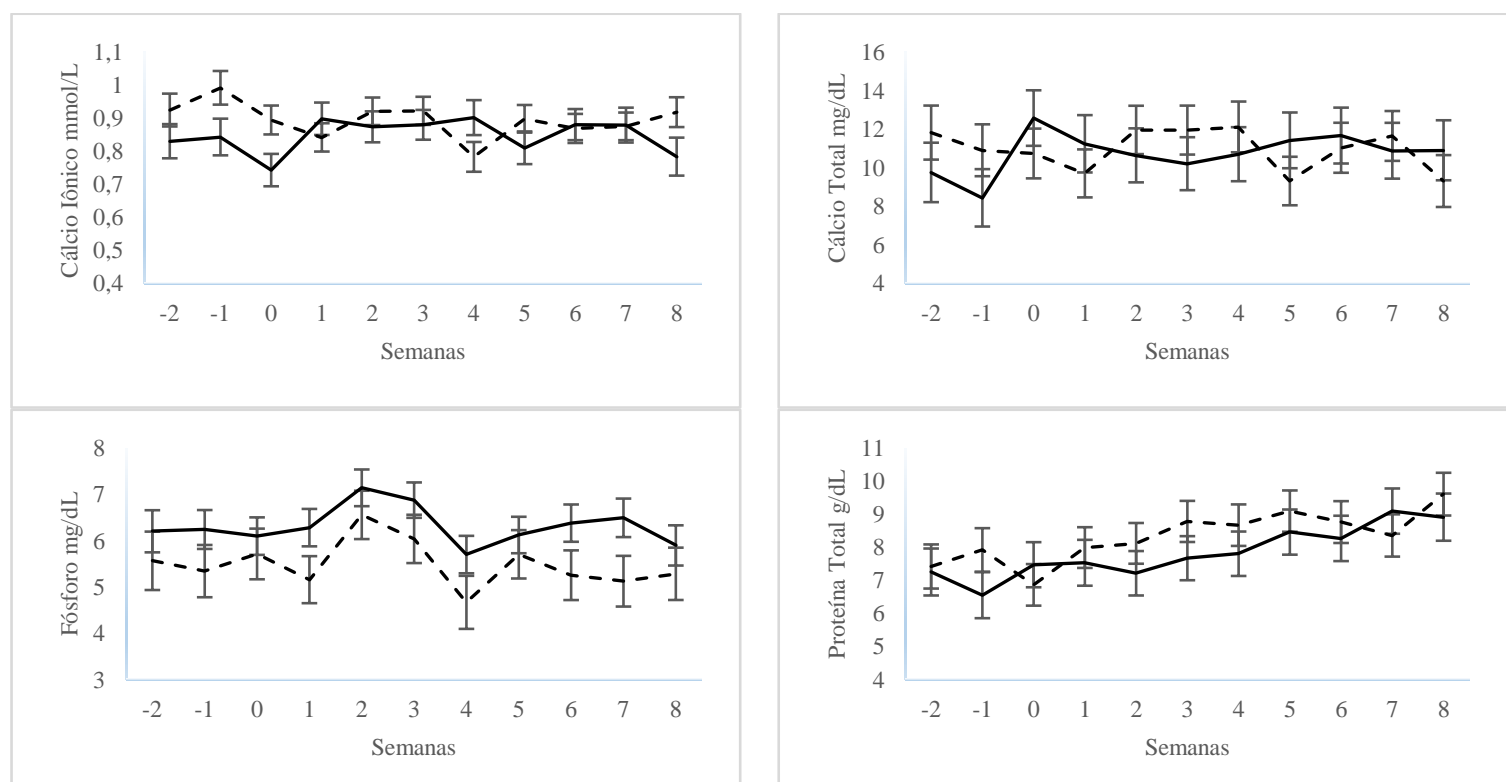

Figura 2. Concentrações séricas de cálcio iônico (A), cálcio total (B), fósforo (C) e proteína total (D) em função das semanas em lactação para vacas Holandês (-) e mestiças Holandês x Jersey (- - -).

\section{DISCUSSÃO}

A maior produção de leite de vacas Holandês em relação às mestiças Holandês $\mathrm{x}$ Jersey pode estar relacionada ao maior peso vivo. Outros trabalhos também verificaram uma maior produção de leite, como o de Heins et al. (2008), considerando os 147 dias iniciais de lactação $(\mathrm{H}=4644$ vs. $\mathrm{HxJ}=4388 \mathrm{~kg}$ de leite $)$.
Alguns estudos demonstraram maior escore de condição corporal (ECC) nas mestiças Holandês $\mathrm{x}$ Jersey em relação às vacas da raça Holandês ao longo da lactação (Prendiville et al., 2009). Porém, no presente trabalho, não houve diferença no ECC entre os grupamentos genéticos (Tab. 2). As vacas Holandês tiveram maior peso vivo durante todo o período de estudo $(\mathrm{P}<0,0001)$, tendo ambos os grupos genéticos perdido peso após o parto (Tab. 2 e Fig. 1B). Durante todo o período de transição estudado, as vacas mestiças 
pesaram aproximadamente $100 \mathrm{~kg}$ a menos do que as vacas puras Holandês. Resultados similares foram encontrados por Prendiville et al. (2011) em sistema baseado a pasto.

Para ambos os grupamentos genéticos, a concentração sérica de glicose permaneceu dentro dos valores de referência, entre 4575mg/dL (González e Silva, 2006) (Tab. 2), e possivelmente isto se deve à elevada regulação em ruminantes (Campos et al., 2007). Desvios acentuados de glicose podem ocorrer em animais doentes, e as concentrações de glicose abaixo de $35 \mathrm{mg} / \mathrm{dL}(1,9 \mathrm{mmol} / \mathrm{L})$ podem ser um sinal de alarme, em que a saúde da vaca pode estar comprometida (González et al., 2000). Campos et al. (2007) encontraram menores valores de glicose na segunda semana de lactação $(39,42 \pm 2,69 \mathrm{mg} / \mathrm{dL})$, havendo, entretanto, nas outras semanas avaliadas, quinta, oitava e $11^{\mathrm{a}}$ semanas, um aumento gradativo dos valores de glicose $(40,86 \pm 3,42 \mathrm{mg} / \mathrm{dL} ; 50,22 \pm 4,32 \mathrm{mg} / \mathrm{dL}$ e $53,64 \pm 3,78 \mathrm{mg} / \mathrm{dL}$, respectivamente), resultados similares aos encontrados no presente trabalho (Fig. 1D). Parece existir um consenso de que a glicose não é o melhor indicador do metabolismo energético, pois ela tem um rigoroso controle hormonal.

Apesar de não haver diferenças entre os grupos genéticos na concentração sérica de BHB, quando se considera todo o período avaliado no presente trabalho, a queda gradativa da concentração sérica de glicose para ambos os grupamentos genéticos foi acompanhada de aumento das concentrações séricas de BHB, desde uma semana antes do parto até as primeiras semanas de lactação (Fig. 1C e D). Os dados de González et al. (2011) corroboram os dados deste trabalho pois apresentam correlação negativa entre BHB e glicose $(r=-0,63)$. O aumento de $\mathrm{BHB}$, concomitante à diminuição do ECC e das concentrações séricas de glicose (Fig. 1), geralmente se associa ao balanço energético negativo, ocorrendo, na maioria das vezes, pela queda da ingestão de matéria seca nessa fase (Ingvartsen e Andersen, 2000). Para compensar o balanço energético negativo, ocorre a mobilização de tecido adiposo, o que se reflete no aumento de ácidos graxos não esterificados (AGNE) no plasma (Schäff et al., 2013) e, como consequência, há aumento das concentrações séricas de BHB, perda de peso vivo e de ECC (Campos et al., 2007).
A tendência para maiores concentrações séricas de BHB nas vacas mestiças Holandês x Jersey em relação às vacas Holandês assemelha-se aos resultados observados por Dal Pizzol et al. (2017), no sul do Brasil, com maiores concentrações séricas de BHB no dia do parto em vacas mestiças Holandês $x$ Jersey $(0,5802 \pm 0,0498 \mathrm{mmol} / \mathrm{L})$ quando comparadas a vacas Holandês $(0,4027 \pm 0,0615 \mathrm{mmol} / \mathrm{L})$, sem diferença entre grupamentos genéticos na nona semana de lactação.

Do pré-parto ao parto, ocorre uma diminuição do colesterol, com aumento nas semanas subsequentes em vacas Holandês e mestiças Holandês $x$ Jersey (Fig. 1E), similar ao observado por Alvarenga et al. (2015) e Kessler et al. (2014). A diminuição de colesterol próximo ao parto pode estar relacionada a uma sobrecarga do fígado, que pode ter sua capacidade de exportação de triglicerídeos prejudicada, ou ao aumento de colesterol no leite. Kessler et al. (2014) verificaram alteração da expressão gênica do fígado com o início da lactação, bem como aumento de enzimas relacionadas à biossíntese de colesterol. No entanto, isso não se refletiu em aumento de colesterol no sangue e sugere que a exportação de triglicerídeos pelo fígado pode estar prejudicada em vacas no início da lactação ou que pode ocorrer um aumento da transferência de colesterol para o leite, e isto se refletir numa concentração de colesterol diminuída no sangue.

A concentração sérica da enzima AST das vacas neste trabalho situou-se dentro dos valores de referência para ambos os grupamentos genéticos (Tab. 3 e Fig. 1F). Houve tendência para maiores concentrações de AST em vacas mestiças Holandês x Jersey em relação às Holandês $(\mathrm{P}=0,0530)$. González e Silva (2006) citam valores entre 78 e 132U/L para AST. A enzima aspartato aminotransferase (AST) em vacas de leite é um indicador de funcionamento hepático e do metabolismo hepático. O aumento da AST no início da lactação pode estar relacionado ao aumento do catabolismo de tecido muscular, para suprir a demanda de energia do organismo, via gliconeogênese (Moreira, et al., 2015).

Houve um aumento considerável da concentração de creatinoquinase $(\mathrm{CK})$ no parto e na primeira semana de lactação em vacas Holandês e mestiças Holandês x Jersey, 
respectivamente (Fig. 1G). Neste trabalho, o aumento da CK pode indicar lesão muscular e ser uma consequência do esforço do parto (González e Silva, 2006; Souza et al., 2008). O aumento concomitante de CK e AST pode indicar dano muscular, enquanto uma elevação de AST associada com CK normal sugere um provável dano hepatocelular (González e Silva, 2006).

Com relação às concentrações séricas de proteína total, não foram encontradas diferenças entre os grupamentos genéticos (Tab. 3). Os valores de referência para proteína total, segundo González e Silva (2006), são de 6,6 a 7,5g/dL, não sendo encontrados, no presente estudo, valores elevados no pós-parto para ambos os grupamentos genéticos (Tab. 3), resultados similares aos encontrados por Cozzi et al. (2011), os quais observaram valores médios de $8,3 \mathrm{~g} / \mathrm{dL}$ para multíparas e de $8,0 \mathrm{~g} / \mathrm{dL}$ para primíparas. Geralmente o aumento das proteínas totais é causado por desidratação e inflamação, enquanto a diminuição é provocada por falhas na síntese ou na absorção, principalmente devido à insuficiência hepática, falhas de absorção intestinal e má nutrição proteica (González e Silva, 2006). De acordo com González e Silva (2006), fisiologicamente pode ocorrer queda nas concentrações de proteína total na semana que antecede o parto, com posterior recuperação após o parto. Essa variação nos valores de proteína total pode ser observada na Fig. 2D para ambos os grupos genéticos.

Não houve diferenças entre os grupamentos genéticos para a concentração sérica de albumina, não havendo diferenças também entre o período de avaliação (Tab. 3). Os resultados encontrados foram semelhantes aos de Alvarenga et al. (2015).

As vacas mestiças Holandês $\mathrm{x}$ Jersey apresentaram maior concentração de cálcio iônico quando comparadas com as vacas Holandês, porém não houve diferença para a concentração de cálcio total no sangue (Tab. 4 e Fig. 2A e B). Observou-se uma queda na concentração do cálcio iônico na semana do parto para ambos os grupos genéticos (Fig. 2A). No parto, a diminuição de cálcio iônico no sangue pode estar relacionada com o início da lactação. Chamberlin et al. (2013) consideram vacas normocalcêmicas aquelas com cálcio iônico $\geq 1,0 \mathrm{mmol} / \mathrm{L}$. González e Silva (2006) consideram que uma diminuição de cálcio no final da gestação e no início da lactação seja devido ao aumento da demanda de cálcio pelo feto e para a síntese de colostro. No presente trabalho, determinaram-se as concentrações de cálcio iônico e cálcio total. No sangue, em torno de 45 a $50 \%$ do cálcio total está na forma livre ou ionizada, e em torno de $40 \%$ dele está complexado a proteínas, principalmente albumina. $\mathrm{O}$ restante do cálcio, em torno de 10 a $15 \%$, está complexado com ânions, como fosfato, sulfato, lactato e citrato. A análise de cálcio iônico é de grande importância, pois é a forma biologicamente ativa e a fração de cálcio prontamente disponível para as células (González e Silva, 2006). Além disso, os receptores de hormônio paratireoidiano (PTH) são responsivos às alterações de cálcio iônico do sangue. Equações de predição de cálcio iônico no sangue nem sempre podem ser adequadas, em especial quando ocorrem alterações nas concentrações de albumina e em casos de desequilíbrios acidobásicos (Calvi e Bushinsky, 2008). Alterações na concentração de proteínas, ânions e variações de $\mathrm{pH}$ podem influenciar e causar uma redistribuição nos pools de cálcio sanguíneo. Em casos de acidose, ocorre uma alteração na constante de equilíbrio do complexo albumina-cálcio, diminuindo a afinidade do cálcio com a albumina e aumentando a concentração de cálcio iônico. Em caso de alcalose, o inverso ocorre, diminuindo a concentração de cálcio iônico no sangue (Jafri et al., 2014). Com o desenvolvimento de eletrodos seletivos cada vez mais precisos para cálcio iônico, a análise direta de cálcio iônico no sangue tem se tornado mais rotineira, principalmente no diagnóstico de hipocalcemia em vacas de leite. Dal Pizzol et al. (2017), no entanto, encontraram valores inferiores de cálcio iônico em vacas mestiças Holandês x Jersey em relação às vacas Holandês $(0,73 \mathrm{mmol} / \mathrm{L}$ versus $1,07 \mathrm{mmol} / \mathrm{L})$.

Os baixos valores de cálcio iônico encontrados no presente estudo podem ter sido influenciados pelo fornecimento de uma dieta catiônica no préparto. No entanto, para evidenciar possíveis diferenças de metabolismo, principalmente de cálcio, entre os grupamentos genéticos avaliados, optou-se pelo fornecimento de dieta com DCAD de $+35,94 \mathrm{mEq} / 100 \mathrm{~g}$ de MS. A concentração de cálcio iônico no sangue é dependente do $\mathrm{pH}$, e o fornecimento de dieta aniônica no pré-parto 
constitui um manejo nutricional com o intuito de acidificar o sangue, causando uma leve acidose metabólica, que aumenta a concentração de cálcio iônico no sangue. Por outro lado, dietas catiônicas, com DCAD positivo, elevam o pH sanguíneo, diminuindo a concentração de cálcio iônico no sangue (Correa et al., 2009).

A relação entre cálcio e fósforo no plasma é inversa, no sentido de que, quando o fósforo diminui, o cálcio aumenta e vice-versa (González e Silva, 2006), relação essa observada no presente estudo (Fig. 2A e C).

\section{CONCLUSÕES}

Vacas mestiças Holandês x Jersey e Holandês perdem peso e condição corporal de modo similar no período pós-parto, o que também é refletido no perfil energético, que não diferiu entre os grupamentos genéticos, com exceção do $\mathrm{BHB}$, o qual teve tendência de ser maior em vacas mestiças Holandês $\mathrm{x}$ Jersey. As concentrações séricas das enzimas AST e CK, assim como da proteína total e da albumina, não diferiram entre os grupamentos genéticos durante o periparto. Vacas mestiças Holandês x Jersey apresentam maiores concentrações de cálcio iônico e menores concentrações de fósforo em relação às vacas Holandês no periparto.

\section{REFERÊNCIAS}

ALVARENGA, E.A.; MOREIRA, G.H.F.A.; FACURY FILHO, E.J.; LEME, F.O.P. et al. Avaliação do perfil metabólico de vacas da raça Holandesa durante o período de transição. Pesqui. Vet. Bras. v.35, p.281-290, 2015.

BAUMAN, D.E.; CURRIE, W.B. Partitioning of nutrients during pregnancy and lactation: a review of mechanisms involving homeostasis and homeorhesis. J. Dairy Sci., v.63, p.15141529, 1980.

CALVI, L M.; BUSHINSKY, D.A. When is it appropriate to order an ionized calcium? J. Am. Soc. Nephrol., v.19, p.1257-1260, 2008.

CAMPOS, R.; GONZÁLEZ, F.; COLDEBELLA, A.R.; LACERDA, L. Indicadores do metabolismo energético no pósparto de vacas leiteiras de alta produção e sua relação com a composição do leIte. Cienc. Anim. Bras,.v.8, p.241-249, 2007.
CHAMBERLIN, W.G.; MIDDLETON, J.R.; SPAIN, J.N.; JOHNSON, G.C. et al. Subclinical hypocalcemia, plasma biochemical parameters, lipid metabolism, postpartum disease, and fertility in postparturient dairy cows. J. Dairy Sci., v.96, p.7001-7013, 2013.

CORREA, L.B.; ZANETTI, M.A.; DEL CLARO, G.R.; PAIVA, F.A. Resposta em parâmetros sanguíneos e urinários de vacas leiteiras ao aumento no balanço catiôn-aniônico da dieta. Arq. Bras. Med. Vet. Zootec., v.61, p.655-661, 2009.

COZZI, G.; RAVAROTTO, L.; GOTTARDO, F.; STEFANI, A.L. et al. Reference values for blood parameters in Holstein dairy cows : effects of parity, stage of lactation, and season of production. J. Dairy Sci., v.94, p.3895-3901, 2011.

DAL PIZZOL, J.; GOMES, I.P.O.; Braun, W.; LISBOA, J.A.N. et al. Comparação entre vacas da raça holandesa e mestiças das raças Holandesa x Jersey quanto à sanidade, imunidade e facilidade de parto. Arq. Bras. Med. Vet. Zootec., v.69, p.955-961, 2017.

FERGUSON, J.D.; GALLIGAN, D.T.; THOMSEN, N. Principal descriptors of body condition score in Holstein cows. J. Dairy Sci., v.77, p.2695-2703, 1994.

GONZÁLEZ, F.D.; MUIÑO, R.; PEREIRA, V.; CAMPOS, R. et al. Relationship among blood indicators of lipomobilization and hepatic function during early lactation in high-yielding dairy cows. J. Vet. Sci., v.12, p.251-255, 2011.

GONZÁLEZ, F.H.D.; BARCELLOS, J.O.; OSPINA, H.; RIBEIRO, L.A.O. (Eds.). Perfil metabólico em ruminantes: seu uso em nutrição e doenças nutricionais. Porto Alegre: UFRGS, 2000, 108p.

GONZÁLEZ, F.H.D.; SILVA, S.C. Introdução à bioquimica clínica veterinária. 2.ed. Porto Alegre: UFGRS, 2006.

HEINS, B.J.; HANSEN, L.B.; HAZEL, A.R. Jersey $\times$ Holstein crossbreds compared with pure Holsteins for body weight, body condition score, fertility, and survival during the first three lactations. J. Dairy Sci., v.95, p.4130-4035, 2012. 
HEINS, B.J.; HANSEN, L.B.; SEYKORA, A.J.; JOHNSON, D.G. et al. Crossbreds of Jersey $\times$ Holstein compared with pure Holsteins for production, fertility, and body and udder measurements during first lactation. J. Dairy Sci., v91, p.1270-1278, 2008.

INGVARTSEN. L.K.; ANDERSEN, J.B. Integration of metabolism and intake regulation: a review focusing on periparturient animals. $J$. Dairy Sci., v.83, p.573-1597, 2000.

JAFRI, L.; KHAN, A.H.; AZEEM, S. Ionized calcium measurement in serum and plasma by ion selective electrodes: comparison of measured and calculated parameters. Ind. J. Clin. Biochem. v.29, p.327-332, 2014.

KESSLER, E.C.; GROSS, J.J.; BRUCKMAIER, R.M.; ALBRECHT, C. Cholesterol metabolism, transport, and hepatic regulation in dairy cows during transition and early lactation. J. Dairy Sci., v.97, p.5481-5490, 2014.

LEBLANC, S. Monitoring metabolic health of dairy cattle in the transition period. J. Reprod., Dev. v.6, p.29-35, 2010.

LOPEZ-VILLALOBOS，N.; GARRICK，D.J.; HOLMES, C.W.; BLAIR, H.T. et al. Effects of selection and crossbreeding strategies on industry profit in the New Zealand dairy industry. J. Dairy Sci., v.83, p.164-172, 2000.

MARTINEZ, N.; SINEDINO, L.D.P.; BISINOTTO, R.S.; RIBEIRO, E.S. et al. Effect of induced subclinical hypocalcemia on physiological responses and neutrophil function in dairy cows. J. Dairy Sci., v.97, p.874-887, 2014.

MERTENS, D.R.; ALLEN, M.; CARMANY, J. et al. Gravimetric determination of amylasetreated neutral detergent fiber in feeds with refluxing in beakers or crucibles: collaborative study. J. AOAC Int., v.85, p.1217-1240, 2002.
MOREIRA, T.F.; FACURY FILHO, E.J.; MENESES, R.M. et al. Arq. Bras. Med. Vet. Zootec., v.67, p.1327-1334, 2015.

NUTRIENT requeriments of dairy cattle. 7.ed. rev. Washinton: Natl. Acad. Press, 2001. 381p.

OFFICIAL methods of analysis of the Association of Official Analytical Chemists, 15.ed. Protein (crude) determination of animal feed: copper catalyst Kjeldahl method (984.13). Gaithersburg, Maryland: AOAC International, 1990.

PRENDIVILLE, R.; PIERCE, K.M.; BUCKLEY, F. An evaluation of production efficiencies among lactating Holstein-Friesian, Jersey, and Jersey x Holstein-Friesian cows at pasture. J. Dairy Sci., v.92, p.6176-6185, 2009.

PRENDIVILLE, R.; PIERCE, K.M.; DELABY, L.; BUCKLEY, F. Animal performance and production efficiencies of Holstein-Friesian, Jersey and Jerseyx Holstein-Friesian cows throughout lactation. J. Liv. Sci., v.138, p.25-33, 2011.

SCHÄFF, C.; BÖRNER, S.; HACKE, S. et al. Increased muscle fatty acid oxidation in dairy cows with intensive body fat mobilization during early lactation. J. Dairy Sci., v.96, p.6449-6460, 2013.

SOUZA., R.M.; GARCIA., N.A.C.R.; BIRGEL, D.B.; JUNIOR, E.H.B. Influência do puerpério e da fase pós-puerperal na função hepática de vacas da raça Holandesa criadas no estado de São Paulo. Cienc. Anim. Bras., v.9, p.140-147, 2008.

WITTWER, F. Diagnóstico dos desequilíbrios metabólicos de energia em rebanhos bovinos. In: GONZÁLEZ, F.H.D.; BARCELLOS, J.O.; OSPINA, H.; RIBEIRO, L.A. O. (Eds.). Perfil metabólico em ruminantes: seu uso em nutrição e doenças nutricionais. Porto Alegre: UFRGS, 2000. p.9-22. 